\title{
THE STANDARDS OF PROOF AS THE BASIS FOR DIFFERENCES IN THE REGULATION OF SIMILAR INSTITUTIONS OF CRIMINAL, CIVIL, ARBITRATION AND ADMINISTRATIVE PROCEEDINGS
}

\author{
Aliya R. Sharipova \\ Bashkir State University, Ufa, Russian Federation
}

Introduction: the division of all procedural institutions into universal, similar and unique ones requires the identification of the factors that determine the branch uniqueness. The purpose of the work is to determine the validity of inter-branch differences in the regulation of the institutions of criminal, civil, arbitration and administrative processes, depending on their own standards of proof. The determinant method of the research was the method of comparative law. A comparison was made of typical situations of proving related offenses under consideration of the criminal and civil or arbitration or administrative procedure. The research also uses the methods of historicism, system-structural analysis and synthesis. Results: the correlation of "standards of proving" and "standards of proof" is determined on the basis of the scientific literature and judicial practice. Through the example of the criminal and civil (arbitration, administrative) cases with similar subjects of proving (the cases of tax crimes and offenses, transport crimes and offenses, fraud and non-repayment of loans, smuggling and non-compliance with the ban on the import and export of goods), different industry requirements are established for the level of verification of the conclusions about the presence or absence of any facts. The cases of the legislative definition of standards of proof for certain legal situations are revealed. Conclusions: serious differences in the levels of proof required by law and judicial practice in different types of legal proceedings dictate the uniqueness of the regulation of a number of procedural institutions in their branch implementation. The sphere of influence of the standards of proof on the branch statutory regulation is not limited by law of evidence.

Key words: standards of proof, judicial law, similar institutions, criminal procedure, arbitration process, civil process, administrative process.

Citation. Sharipova A.R. The Standards of Proof as the Basis for Differences in the Regulation of Similar Institutions of Criminal, Civil, Arbitration and Administrative Proceedings. Legal Concept = Pravovaya paradigma, 2021, vol. 20, no. 1, pp. 130-136. (in Russian). DOI: https://doi.org/10.15688/lc.jvolsu.2021.1.20

УДК 343.1

ББК 67.410 .2

Дата поступления статьи: 22.01.2021

Дата принятия статьи: 12.02.2021

\section{СТАНДАРТЫ ДОКАЗАННОСТИ КАК ОСНОВАНИЯ РАЗЛИЧИЙ В РЕГУЛИРОВАНИИ СХОДНЫХ ИНСТИТУТОВ УГОЛОВНОГО, ГРАЖДАНСКОГО, АРБИТРАЖНОГО И АДМИНИСТРАТИВНОГО ПРОЦЕССА}

\author{
Алия Рашитовна Шарипова \\ Башкирский государственный университет, г. Уфа, Российская Федерация
}


соотношение «стандартов доказывания» и «стандартов доказанности» на основании научной литературы и судебной практики. На примере уголовных и гражданских (арбитражных, административных) дел со схожими предметами доказывания (дела о налоговых преступлениях и правонарушениях, о транспортных преступлениях и правонарушениях, о мошенничестве и невозвращении займа, о контрабанде и несоблюдении запрета на ввоз и вывоз товара) установлены разные отраслевые требования к уровню верификации выводов о наличии или отсутствии каких-либо фактов. Выявлены случаи законодательного определения стандартов доказанности для отдельных правовых ситуаций. Выводы: серьезные различия в требуемых законом и судебной практикой в разных видах судопроизводства уровнях доказанности диктуют своеобразие регламентации целого ряда процессуальных институтов в их отраслевом воплощении. Сфера влияния стандартов доказанности на отраслевое нормативное регулирование не ограничена доказательственным правом.

Ключевые слова: стандарты доказанности, судебное право, аналогичные институты, уголовный процесс, арбитражный процесс, гражданский процесс, административный процесс.

Цитирование. Шарипова А. Р. Стандарты доказанности как основания различий в регулировании сходных институтов уголовного, гражданского, арбитражного и административного процесса // Legal Concept = Правовая парадигма. -2021. - Т. 20, № 1. - C. 130-136. - DOI: https://doi.org/10.15688/lc.jvolsu.2021.1.20

\section{Введение}

Подавляющее большинство судебных институтов уголовного, гражданского, арбитражного и административного процессов универсальны, то есть настолько схожи по своей природе, обусловленной единой сущностью правосудия, что нуждаются в одинаковой регламентации. Иначе дело обстоит с «аналогичными» процессуальными институтами, межотраслевое родство которых допускает существенное своеобразие в регулировании. Это своеобразие не является произвольно возникшим, оно всегда связано с какими-то существенными внутрипроцессуальными особенностями, характерными для каждого вида судопроизводства в отдельности. Полагаем возможным попытаться аргументировать обоснованность различий в ряде схожих институтов указанных отраслей собственными стандартами доказанности.

\section{Соотношение стандартов доказывания и стандартов доказанности}

В литературе достаточно много в последнее время освещают вопросы, посвященные стандартам доказывания, объединяя под этим названием, по англо-саксонскому примеру, «совокупность критериев оценки доказательств, подлежащих применению судами при рассмотрении дел определенной категории и позволяющих, в частности, определить достаточность доказательств необходимой степени достоверности (для того или иного правового вывода)» [12, с. 135]. Вошел новый термин и в лексикон Верховного Суда РФ, дополняясь характеристиками «пониженный», «повышенный», «строгий» и др., на что обращают внимание исследователи этого явления [1]. Как правило, помимо вопросов достаточности доказательств, отношение к которой в разных видах процессов нас сейчас интересуют, в «стандарт доказывания» включают и критерии допустимости и достоверности. Не желая углубляться в эти дискуссии, ограничимся только стандартами доказанности, составляющими реальное межотраслевое различие.

Близким к нашему пониманию стандартов доказанности является определение «позитивного стандарта доказывания», данное А.Г. Карапетовым, А.С. Косаревым: это степень убедительности комплекса доказательств, предъявленных стороной, несущей бремя доказывания, воспринимаемая судами как достаточная и используемая на практике [8]. Они же отмечают, что поиски истины на определенном этапе прекращаются вследствие ограниченных времени ресурсов суда [8], а также ссылаются на «Экономический анализ права» Ричарда Познера: «на каком-то этапе предельные социальные издержки на поиск, представление, исследование и оценку доказательств начинают превышать социальные выгоды от приращения убедительности позиции сторон по фактам спора и снижения вероятности ошибочного установления фактов» [13, p. 819-820] (цит. по: [8]). 


\section{ПРОЦЕССУАЛЬНОЕ ПРАВО: ВОПРОСЫ ТЕОРИИ И ПРАВОПРИМЕНЕНИЯ}

Помимо того, что эти утверждения справедливы, эта справедливость своеобразна по отношению к каждому из видов судебных процессов. Вполне обоснованно для обвинения в совершении террористического акта собрать и исследовать данные биллинга и сотен камер наблюдения в отношении множества людей (а затем оценивать их в суде), но довольно странно делать то же самое, чтобы подтвердить участие в несанкционированном митинге (ст. 20.2 КоАП), хотя «технически» выявление людей, находившихся в определенном месте в определенное время, по этим деяниям очень схоже.

С другой стороны, в арбитражном процессе существует такой уникальный инструмент доказывания как соглашение по фактическим обстоятельствам, позволяющий сторонам экономить процессуальные усилия и не тратить их на установление того, о чем между ними спора нет. Это очень удобно с точки зрения доказывания, но практически немыслимо по уголовным делам, поскольку предполагает принципиально иной стандарт доказанности.

\section{Различия стандартов доказанности в процессуальных отраслях}

В уголовных делах об экономических преступлениях предмет доказывания имеет значительное сходство со смежными гражданскими, арбитражными, налоговыми, административными и иными спорами. Такими «смежными» делами являются, например, уголовные дела о мошенничестве и гражданские или арбитражные дела о неисполнении обязательств по договору, уголовные дела о налоговых преступлениях и арбитражные дела о налоговых правонарушениях, и многие другие подобные «пары».

Разные стандарты доказанности одних и тех же обстоятельств в этих парах легко можно продемонстрировать следующими примерами. Для установления факта принятия наличных денег во исполнение заключенного договора в гражданском или арбитражном споре, как правило, достаточно собственноручной расписки их получателя. По делу об обвинении в мошенничестве (состоявшегося при «камуфляже» точно такого же договора, только с изначальным намерением не испол- нять его) прием денег от потерпевшего устанавливается, помимо расписки, свидетельскими показаниями, заключением эксперта о принадлежности текста и подписи на расписке рукой обвиняемого. И эти дополнительные доказательства присутствуют даже в уголовных делах с признанием вины обвиняемым и даже явкой с повинной [4]! Более того, даже внутри гражданских дел действуют разные стандарты: по делам о взыскании займа расписки достаточно [3], а в делах о банкротстве - нет. При установлении требований кредиторов в деле о банкротстве судам следует исходить из того, что установленными могут быть признаны только требования, в отношении которых представлены достаточные доказательства наличия и размера задолженности. Признавая расписку недостаточным доказательством, не соответствующим «повышенному стандарту доказывания», арбитражный суд, в частности, указывает следующее: при оценке достоверности факта наличия требования, основанного на передаче должнику наличных денежных средств, подтверждаемого только его распиской или квитанцией к приходному кассовому ордеру, суду надлежит учитывать, позволяло ли финансовое положение кредитора (с учетом его доходов) предоставить должнику соответствующие денежные средства, имеются ли в деле удовлетворительные сведения о том, как полученные средства были истрачены должником, отражалось ли получение этих средств в бухгалтерском и налоговом учете и отчетности [11].

Обычной практикой доказывания по уголовным делам о налоговых преступлениях является проведение судебно-экономической экспертизы. Ее заключением устанавливаются все элементы налогообложения со ссылкой и исходя из первичных документов налогоплательщика, а также данных, полученных в результате встречных проверок его контрагентов и банков. Таким способом принято подтверждать совершение объективной стороны налоговых преступлений. Несмотря на то, что мы относимся к этому резко негативно и считаем подобную практику наносящей урон состязательности в суде, вероятно она призвана как раз поддержать традиционно повышенный стандарт доказанности по уголовным делам. По мысли правоприменителя, поддер- 
живающего ее, заключение экспертизы - практически самое «надежное» доказательство, поэтому и назначают ее не только ради специальных познаний, но и для придания весомости собранной доказательственной базы.

Пример транспортных правонарушений так же показывает разность стандартов доказанности. Так, при одинаковых обстоятельствах совершения нарушения правил дорожного движения, не пресеченного сразу же сотрудниками правоохранительных органов, факт управления транспортным средством конкретным лицом устанавливается по-разному. Так, ст. 2.6.1. КоАП установлено, что административной ответственности подлежат собственники транспортных средств в случае фиксации административных правонарушений техническими средствами в автоматическом режиме. Если в ходе обжалования постановления о привлечении к ответственности собственник докажет, что транспортное средство было не под его управлением, то он освобождается от ответственности. Не будем сейчас критиковать законоположение, «освобождающее» лицо от ответственности, которой оно не должно было подлежать, но заметим, что введено оно ради придания законной силы очевидно низкому стандарту доказанности по этой группе дел (жалобы по которым могут рассматриваться и в суде). По уголовным делам о преступлениях, связанных с управлением транспортным средством, установления права собственности на него, разумеется, недостаточно для обвинения собственника. Недостаточно для этого и отсутствия от него заявления об угоне: обычно используются свидетельские показания лиц, видевших, кто управлял транспортом в момент совершения преступления, непосредственно до и после него, заключение по результатам проведения видеотехнической экспертизы записей автомобильных видеорегистраторов, исследование принадлежности отпечатков пальцев на руле и следов крови на подушках безопасности автомобиля и др. [2].

Законодательством предусмотрено множество смежных административных правонарушений и преступлений. Еще одна подобная пара - несоблюдение запретов и ограничений на ввоз и вывоз товаров с таможенной территории и контрабанда наркотических средств и подобных им веществ, прекурсо- ров и растений, соответствующие ст. 16.3 КоАП и ст. 229.1 УК. Административное правонарушение устанавливается на основании письменных документов, исходящих, большей частью, от самого нарушителя «запретов и ограничений»: противозаконное деяние подразумевает, нарушение в процедуре оформления разрешительных бумаг, необходимых для перемещений товаров, в том числе связанных с наркотиками. Действительное физическое существование этих химических веществ путем отбора проб и их исследования не устанавливается [10]. Разумеется, при доказывании совершения уголовно-правового «аналога» этого деяния все иначе: проводится судебнохимическая экспертиза [6].

Несмотря на то, что презумпция невиновности предусмотрена не только в УПК, но и в КоАП, для уголовного процесса она задает максимальные стандарты доказанности, в том числе через обязанность обвинения опровергать доводы защиты, не предусмотренную более нигде. Другие асимметричные случаи распределения бремени доказывания освобождают защищающуюся сторону от необходимости доказывать свою невиновность, но оставляют другой стороне на усмотрение, как именно доказывать вину, без уточнения об опровержении доводов защиты (ст. 1.5 КоАП, ч. 1 ст. 65 АПК, ч. 2 ст. 62 КАС).

Есть примеры и законодательного снижения стандарта доказанности для уголовных дел. Так, примечанием 2 к статье 264 УК установлено, что в целях применения ст. 263, 264, 264.1 под лицом, находящимся в состоянии опьянения, признается тот, чье опьянение установлено лабораторно, а также «лицо, уnравляюшее транспортным средством, не выполнивщее законного требования уполномоченного должностного лица о прохождении медицинского освидетельствования на состояние опьянения в порядке и на основаниях, предусмотренных законодательством Российской Федерации». Никакой уголовноправовой логике не подвластна юридическая фикция признания лицом в состоянии опьянения того, кто отказался от освидетельствования. И никакой уголовно-правовой логики здесь и нет: она, скорее, уголовно-процессуальная. Это способ облегчения доказывания для органов предварительного расследования. Сле- 
ды алкоголя и других опьяняющих веществ в организме человека недолговечны, и если подозреваемый откажется сдать биологические образцы для исследования, то спустя то время, пока их удастся получить помимо его воли, доказательственные возможности будут упущены. Эта проблема не только отечественного правопорядка: по утверждению К.С. Баканова, в Республике Беларусь и Германии существуют правовые возможности освидетельствования и медицинского освидетельствования человека против его воли [7]. Устанавливать же опьянение через косвенные доказательства (свидетельства употребления каких-то веществ, например) хлопотно и ненадежно, поэтому законодатель просто признал тех, кто отказывается от освидетельствования, «пьяными». Как ни странно, в отдельных случаях эта «льгота» правоприменителю оборачивается против него. Всякий случай законодательного установления возможности доказывания какого-либо обстоятельства только определенным доказательством должен быть тщательно выверен. Так, в статье Т.И. Наумовой, В.И. Сивцева описана проблема, существующая в самом большом регионе России - Республике Саха (Якутия): в связи с удаленностью населенных пунктов друг от друга зачастую нет возможности провести медицинское освидетельствование водителей, которые не отказываются от него. Но ни простым освидетельствованием, проводимым ГИБДД, ни свидетельскими показаниями, ни собственными показаниями обвиняемого о нахождении его в состоянии опьянения подтверждать последнее нельзя [9].

Случаи законодательного снижения требований к достаточной совокупности доказательств, которой принято устанавливать какие-то факты, как правило, болезненно воспринимаются общественностью. Это подтверждает и пример с признанием отказавшихся от освидетельствования водителей находящимися в состоянии опьянения ${ }^{1}$, и пример привлечения к административной ответственности собственников автомобилей, когда правонарушения установлены в автоматическом режиме средствами фото и видеофиксации.

Позитивно принимаются обычно примеры повышения стандартов доказанности. Так, до появления возможности широкого проведе- ния исследований ДНК установление отцовства проводилось по косвенным доказательствам, подтверждающим отношения между матерью ребенка и каким-то мужчиной (совместное проживание, переписка, ведение общего хозяйства), и отношения его к ребенку (участие в воспитании, в расходах на его содержание) и др. Теперь все чаще суды прибегают к назначению генно-молекулярной экспертизы для определения биологического отцовства [5]. Разумеется, это дает более высокую гарантию установления истины по делу, но и предполагает несение сторонами (и в каких-то случаях государством) дополнительных расходов.

Любое повышение стандарта доказанности приводит к удорожанию судебного процесса, поэтому назвать тенденцию постоянного повышения желательной можно лишь при условии готовности общества вкладывать все болыше средств в судопроизводство. В этом заключается главная причина невозможности распространения высочайшего стандарта доказанности, принятого в уголовном процессе, на другие отрасли. Разница в стандартах доказанности обусловливает своеобразие не только и не столько в отдельных институтах доказательственного права. Именно собственные стандарты доказанности каждой из процессуальных отраслей делают аналогичными такие институты, кажущиеся универсальными, как принципы судопроизводства, участники судопроизводства, обвинение (иск), защита от обвинения (иска).

\section{ПРИМЕЧАНИЕ}

1 Логика оправдания этого законоположения через недопустимость установления более выгодного положения для лиц, уклоняющихся от выполнения законного требования сотрудника правоохранительного органа, по сравнению с лицами, выполняющими требования (и соответственно, проходящими медицинское освидетельствование), нам известна.

\section{СПИСОК ЛИТЕРАТУРЫ}

1. Аргунов, В. В. О так называемых стандартах доказывания применительно к отечественному судопроизводству / В. В. Аргунов, М. О. Долова // Вестник гражданского процесса. - 2019. - № 2. C. 76-104. 
2. Апелляционное постановление Ивановского областного суда от 2 октября 2019 г. по делу № 22-1604/2019. - Доступ из СПС «КонсультантПлюс» (дата обращения: 21.01.2021).

3. Апелляционное определение Липецкого областного суда от 25 июня 2018 г. по делу № 332134/20182019. - Доступ из СПС «КонсультантПлюс» (дата обращения: 21.01.2021).

4. Апелляционное определение Московского городского суда от 7 октября 2019 г. по делу № 10-13537/20192019. - Доступ из СПС «КонсультантПлюс» (дата обращения: 21.01.2021).

5. Апелляционное определение Московского городского суда от 28 февраля 2013 г. по делу № 11-44212019. - Доступ из СПС «КонсультантПлюс» (дата обращения: 21.01.2021).

6. Апелляционное определение Первого апелляционного суда общей юрисдикции от 7 августа 2020 г. по делу № 55-1281/20202019. - Доступ из СПС «КонсультантПлюс» (дата обращения: 21.01.2021).

7. Баканов, К. С. Отказ водителя транспортного средства от медицинского освидетельствования и его взаимосвязь с потреблением наркотических средств / К. С. Баканов // Законы России: опыт, анализ, практика. - 2018. - № 11. - С. 81-86.

8. Карапетов, А. Г. Стандарты доказывания: аналитическое и эмпирическое исследование / А. Г. Карапетов, А. С. Косарев // Вестник экономического правосудия Российской Федерации. Приложение к Ежемесячному журналу. - 2019. - № 5. Специальный выпуск. - С. 3-96.

9. Наумова, Т. И. Проблемы квалификации деяний, предусмотренных ст.ст. 264 и 264.1 УК / Т. И. Наумова, Н. И. Сивцев // Законность. 2019. - № 7. - С. 50-52.

10. Постановление Арбитражного суда Московского округа от 10 апреля 2020 г. № Ф05-3501/2020 по делу № А41-62541/20192019. - Доступ из СПС «КонсультантПлюс» (дата обращения: 21.01.2021).

11. Постановление Первого арбитражного апелляционного суда от 1 октября 2020 г. № 01АП5380/2020 по делу № A11-14941/20192019. - Доступ из СПС «КонсультантПлюс» (дата обращения: 21.01.2021).

12. Смола, А. А. Стандарты, доказывание и Верховный Суд / А. А. Смола // Вестник экономического правосудия Российской Федерации. 2018. - № 8. - C. 129-165.

13. Posner, R. A. Economic Analysis of Law / R. A. Posner. $-8^{\text {th }}$ ed. - N. Y., 2011.

\section{REFERENCES}

1. Argunov V.V., Dolova M.O. O tak nazyvaemykh standartakh dokazyvaniya primenitelno $\mathrm{k}$ otechestvennomu sudoproizvodstvu [On the Socalled Standards of Proof in Relation to Domestic Legal Proceedings]. Vestnik grazhdanskogo protsessa [Bulletin of civil procedure], 2019, no. 2, pp. 76-104.

2. Apellyacionnoe postanovlenie Ivanovskogo oblastnogo suda ot 2 oktyabrya 2019 g. po delu № 22$1604 / 2019$ [The Appeal Decision of the Ivanovo Regional Court Dated October 2, 2019 in case No. 221604/2019]. Access from the reference legal system "ConsultantPlus» (accessed 21 January 2021).

3. Apellyacionnoe opredelenie Lipeckogo oblastnogo suda ot 25 iyunya 2018 g. po delu № 332134/20182019 [The Appeal Ruling of the Lipetsk Regional Court Dated June 25, 2018 in case No. 332134 / 20182019]. Access from the reference legal system "ConsultantPlus» (accessed 21 January 2021).

4. Apellyacionnoe opredelenie Moskovskogo gorodskogo suda ot 7 oktyabrya 2019 g. po delu № 10 13537/20192019 [The Appeal Ruling of the Moscow City Court of October 7, 2019 in Case No. 10-13537 / 20192019]. Access from reference legal system «ConsultantPlus» (accessed 1 December 2021).

5. Apellyacionnoe opredelenie Moskovskogo gorodskogo suda ot 28 fevralya 2013 g. po delu № 1144212019 [Appellate Ruling of the Moscow City Court Dated February 28, 2013 in Case No. 11-44212019]. Access from the reference legal system "Consultant Plus» (accessed 21 January 2021).

6. Apellyacionnoe opredelenie Pervogo apellyacionnogo suda obshchej yurisdiktsii ot 7 avgusta 2020 g. po delu № 55-1281/20202019 [Appellate Ruling of the First Court of Appeal of General Jurisdiction of August 7, 2020 in Case No. 55-1281/ 20202019]. Access from the reference legal system «ConsultantPlus» (accessed 21 January 2021).

7. Bakanov K.S. Otkaz voditelya transportnogo sredstva ot meditsinskogo osvidetelstvovaniya i ego vzaimosvyaz s potrebleniem narkoticheskikh sredstv [Refusal of a Vehicle Driver From a Medical Examination and its Relationship with Drug Use]. Zakony Rossii: opyt, analiz, praktika [Laws of Russia: Experience, Analysis, Practice], 2018, no. 11, pp. 81-86.

8. Karapetov A.G., Kosarev A.S. Standarty dokazyvaniya: analiticheskoe i empiricheskoe issledovanie [Evidence Standards: Analytical and Empirical Research]. Vestnik ekonomicheskogo pravosudiya Rossiiskoi Federatsii. Prilozhenie $k$ Ezhemesiachnomu zhurnalu [Bulletin of Economic Justice of the Russian Federation. Appendix to the Monthly Magazine], 2019, no. 5. Special issue, pp. 3-96.

9. Naumova T.I., Sivtsev N.I. Problemy kvalifikatsii deyanij, predusmotrennykh st.st. 264 i 264.1 UK [Problems of Qualification of the Acts Under Art. Art. 264 and 264.1 of the Criminal Code]. Zakonnost [Legality], 2019, no. 7, pp. 50-52. 


\section{ПРОЦЕССУАЛЬНОЕ ПРАВО: ВОПРОСЫ ТЕОРИИ И ПРАВОПРИМЕНЕНИЯ}

10. Postanovlenie Arbitrazhnogo suda Moskovskogo okruga ot 10 aprelya 2020 g. № F053501/2020 po delu № A41-62541/20192019 [Ruling of the Arbitration Court of the Moscow District of April 10, 2020 No. F05-3501 / 2020 in Case No. A41-62541/ 20192019]. Access from the reference legal system «ConsultantPlus» (accessed 21 January 2021).

11. Postanovlenie Pervogo arbitrazhnogo apellyacionnogo suda ot 1 oktyabrya $2020 \mathrm{~g}$. № 01AP-5380/2020 po delu № A11-14941/20192019 [Ruling of the First Arbitration Court of Appeal of
October 1, 2020 No. 01AP-5380/2020 in Case No. A11-14941 / 20192019]. Access from the reference legal system «ConsultantPlus» (accessed 21 January 2021).

12. Smola A.A. Standarty, dokazyvanie i Verhovnyj Sud [Standards, Proof and the Supreme Court]. Vestnik ekonomicheskogo pravosudiya Rossiiskoi Federatsii [Bulletin of Economic Justice of the Russian Federation], 2018, no. 8, pp. 129-165.

13. Posner R.A. Economic Analysis of Law. $8^{\text {th }} \mathrm{ed}$. N.Y., 2011.

\section{Information About the Author}

Aliya R. Sharipova, Candidate of Sciences (Jurisprudence), Associate Professor, Department of Criminal Law and Procedure, Bashkir State University, Zaki Validi St, 32, 450076 Ufa, Russian Federation, nord-wind23@mail.ru, rector@bsunet.ru,https://orcid.org/0000-0003-3254-5577

\section{Информация об авторе}

Алия Рашитовна Шарипова, кандидат юридических наук, доцент кафедры уголовного права и процесса, Башкирский государственный университет, ул. Заки Валиди, 32, 450076 г. Уфа, Российская Федерация, nord-wind23@mail.ru, rector@bsunet.ru, https://orcid.org/0000-0003-3254-55770 